\title{
Tower bio-vermifilter system for rural wastewater treatment: bench-scale, pilot-scale, and engineering applications
}

\author{
E. Nie $\cdot$ D. Wang $\cdot$ M. Yang $\cdot$ X. Luo \\ C. Fang $\cdot$ X. Yang $\cdot$ D. Su $\cdot$ L. Zhou \\ Z. Zheng
}

Received: 9 April 2013/Revised: 22 November 2013/Accepted: 9 December 2013/Published online: 9 January 2014

(C) Islamic Azad University (IAU) 2013

\begin{abstract}
This paper presents a systematic study of a novel tower bio-vermifilter system for rural wastewater treatment at three scales: bench-scale, pilot-scale, and engineering applications. First, three types of bioreactors were tested in the bench-scale experiments: earthworm bioreactor, soil filter, and one-stage bio-vermifilter. Experiments with the earthworm bioreactor and soil filter determined the optimum earthworm density and soil layer depth to be $12.5 \mathrm{~g} / \mathrm{L}$ and $40 \mathrm{~cm}$, respectively. The onestage bio-vermifilter's poor performance in removing nitrogen and phosphorous led to several improvements in the design of the pilot tower bio-vermifilter system including the addition of one anaerobic biofilter for pretreatment, the use of two stages of bio-vermifilters, and the replacement of gravel with ceramsite in the media. Second, a pilot tower bio-vermifilter system built in Yixing City of Jiangsu province showed a good performance in the removal of chemical oxygen demand, ammonium nitrogen, and phosphorous. However, the system's removal of total nitrogen showed considerable fluctuations, possibly due to the low ratio of carbon to nitrogen in its stage two bio-
\end{abstract}

E. Nie $\cdot$ D. Wang $\cdot$ M. Yang $\cdot$ X. Luo $\cdot$ X. Yang $(\bowtie)$.

L. Zhou $\cdot$ Z. Zheng

Department of Environmental Science and Engineering, Fudan University, Shanghai 200433, People's Republic of China

e-mail: xiaoying@fudan.edu.cn

C. Fang

College of Environmental Science and Engineering, Anhui

Normal University, Wuhu 241002, People's Republic of China

D. $\mathrm{Su}$

School of the Environment, Nanjing University, Nanjing

210046, People's Republic of China vermifilter. Finally, four operating tower bio-vermifilter systems in three basins of China were evaluated and compared with two other rural sewage treatment technologies in terms of economic costs and pollutant removal performance. Comparison results show that the tower biovermifilter system is a versatile system that can work effectively under a variety of natural and socioeconomic conditions at a reasonable cost.

Keywords Sewage $\cdot$ Phosphorus $\cdot$ Nitrogen $\cdot$ Chemical oxygen demand $\cdot$ Pollutant removal $\cdot$ Evaluation

\section{Introduction}

Despite Chinese government's tremendous water pollution control efforts in the past decade, eutrophication remains serious in the country's major lakes and rivers with chemical oxygen demand (COD), biochemical oxygen demand (BOD), and total phosphorus (TP) as the main pollutants (CMEP 2011). Across China, the frequency and influenced areas of algae blooms have been increasing (Duan et al. (2009); Otten et al. (2012); Wang et al. (2011a)), harming the nation's aquatic ecosystem integrity (Paerl and Huisman (2008)), fish culture (Paerl and Huisman (2008), Wei et al. (2001)), recreational resources (Otten et al. (2012), Wei et al. (2001)), and public health. For example, a break-out of algae bloom in the Lake Taihu has led to more than one million people without safe drinking water in 2007 (Duan et al. (2009); Guo (2007); Yang et al. (2008)).

Algae bloom has been recognized as the result of excessive nitrogen and phosphorus inputs (Conley et al. (2009)) from municipal and industrial sewerage (Xin and Stone (2010), Paerl and Huisman (2008)), rural domestic 
wastewater, livestock sewage, and agricultural runoff. Unlike most Western countries, the proportion of nutrient inputs from rural domestic wastewater is very large in China partly due to its large rural population base. According to the sixth Chinese population census, the nation's rural population was 674.15 million in 2010, accounting for $50.3 \%$ of its national total population compared to $17.7 \%$ in USA (Ma (2012)).

In addition, wastewater from the large number of rural households is mostly discharged into the surroundings either without or only with minimal treatment in China (Yang et al. (2012b)). Large amount of discharge and little treatment coverage have caused rural domestic wastewater to become one major nonpoint water pollution source in many regions of China, and it sometimes has surpassed agriculture and livestock in terms of the amount of pollutants discharged into the ambient water environment (Wang et al. (2010b); Zhang et al. (2009)).

Because of China's large rural population and dispersed distribution, it is uneconomical and unrealistic to gather sewage from individual rural household for central treatment as done in municipal sewage treatment. Decentralized wastewater treatment has been explored as an alternative for reducing pollutant load from rural regions, which ideally could cater the special needs of rural sewage treatment such as tolerance of variable pollutant loads, stable and high removal efficiencies of nutrients and organic compounds, and low construction and operation costs. There are mainly two types of decentralized wastewater treatment technologies for rural sewage treatment: (1) activated sludge process such as packed bed biofilm reactor (Liang et al. (2010a)), cyclic activated sludge system (CASS) (Hao et al. (2010)), and anaerobic sludge reactor; (2) land treatment process such as stabilization pond (Verbyla et al. (2013)), constructed wetland (Li et al. (2009), Wu et al. (2011)), and soil infiltration system (Liang et al. (2010b)).

Bio-vermifilter, a land treatment process that has been developed and improved in the past decade, has the advantages of low energy consumption (Sinha et al. (2008), Wang et al. (2011c)) and easy maintenance (Wang et al. (2011c)). In 2008, the technology was appraised as one of the five outstanding achievements in the first phase of Chinese National Key Water Pollution Control Program of the Lake Taihu launched by Chinese Ministry of Science and Technology. A series of bench-scale studies have been conducted to understand the mechanisms for the removal of organic matters, nitrogen, and phosphorus (Fang et al. (2011), Wang et al. (2011c)) in the bio-vermifilter. In addition, bench-scale studies have also been conducted to evaluate the impacts of operation conditions on the biovermifilter's pollutant removal performance, such as hydraulic loads (Fang et al. (2011)), hydraulic residence time, and microbial community diversity (Wang et al. 2011b, 2013).

Previous studies on the bio-vermifilter have been mostly bench-scale focused on theoretical research of the mechanisms for pollutant removal, especially COD and nitrogen. In addition to theoretical understandings of the pollutant removal processes, optimization of the system design and operation conditions is indispensible to successful application of the technology in the real world. In view of the gap, this paper presents a systematic study of the bio-vermifilter ranging from benchscale experiments to pilot-scale and engineering applications to facilitate the technology's adoption in rural sewage treatment. Bench-scale experiments were designed to guide the design and operation of pilot-scale and engineering applications. Pilot-scale and engineering applications were examined to evaluate the technology's stability and efficiency in the removal of nutrients and organic compounds, and analyze its suitability for rural sewage treatment under a variety of operation conditions. Bench-scale and pilot-scale experiments were conducted from April 2010 to October 2012. Bench-scale experiments were conducted at the Fudan University campus, while pilot-scale experiments were conducted in a rural village of the Yixing City in Jiangsu province of Eastern China.

\section{Materials and methods}

Bench-scale experiments

\section{Bioreactors}

Three types of bioreactors were designed and used in the bench-scale experiments, which were all made of polymethyl methacrylate: earthworm bioreactor, soil filter, and one-stage bio-vermifilter. Earthworm bioreactors with a dimension of $30 \mathrm{~cm} \times 5 \mathrm{~cm} \times 40 \mathrm{~cm}$ were used to determine the most appropriate earthworm density appropriate for wastewater treatment. Each earthworm bioreactor was filled with artificial soil (AS), which was made of sawdust and soil in a ratio of 3 to 1 in volume. The earthworm bioreactors were inoculated with Eisenia foetida at an initial density of $0,2.5,5,7.5,10,12.5$, and $15 \mathrm{~g} / \mathrm{L}$ (fresh weight basis).

Previous studies indicate that phosphorous is mainly removed through medium adsorption (Arias et al. 2001; Del Bubba et al. 2003; Seo et al. 2005). A soil filter was set up to determinate the appropriate soil layer depth for phosphorous removal. It was basically a cylinder of $10 \mathrm{~cm}$ in diameter and $200 \mathrm{~cm}$ in height with 10 vertically evenly distributed sampling holes $(1 \mathrm{~cm}$ in diameter). It contained 
a 200-cm layer of AS inoculated with Eisenia foetida at an initial density of $12.5 \mathrm{~g} / \mathrm{L}$.

Artificial wastewater (AW) was fed into the above two bioreactors in a batch mode controlled by a timer. AW was made by first mixing peptone, beef extract, carbamide, $\mathrm{NaCl}, \mathrm{CaCl}_{2} \cdot 2 \mathrm{H}_{2} \mathrm{O}, \mathrm{MgSO}_{4} \cdot 7 \mathrm{H}_{2} \mathrm{O}$, and $\mathrm{K}_{2} \mathrm{HPO}_{4}$ in a wastewater tank, and then diluted to emulate the pollutant concentrations of rural sewage (applied COD $=400 \mathrm{mg} / \mathrm{L}$, total nitrogen $(\mathrm{TN})=32 \mathrm{mg} / \mathrm{L}$, ammonium nitrogen $\left.\left(\mathrm{NH}_{4}{ }^{+}-\mathrm{N}\right)=24 \mathrm{mg} / \mathrm{L}, \mathrm{TP}=5 \mathrm{mg} / \mathrm{L}\right)$. During the experiments with the two bioreactors, the hydraulic load was kept at $1 \mathrm{~m}^{3} /\left(\mathrm{m}^{2} \cdot \mathrm{d}\right)$. Average pollutant removal efficiencies were estimated after an initial acclimation of 28 days.

Based on the experiment results with the earthworm bioreactors and the soil filter, one-stage bio-vermifilter was designed and built (Fig. 1). The one-stage bio-vermifilter was operated over a period of 10 months to study the phosphorus removal processes in the soil layer, as well as evaluate its pollutant removal performance. With a dimension of $44 \mathrm{~cm} \times 34 \mathrm{~cm} \times 120 \mathrm{~cm}$, the one-stage bio-vermifilter contained a $25-\mathrm{cm}$ layer of cobble (20-40 $\mathrm{mm}$ in diameter), a $30-\mathrm{cm}$ layer of gravel (15-30 $\mathrm{mm}$ in diameter), a $10-\mathrm{cm}$ layer of gravel (2-10 $\mathrm{mm}$ in diameter), a 20-cm layer of sand $(0.2-2 \mathrm{~mm}$ in diameter), and a 40-cm layer of AS from the bottom to the top. Its soil layer was also inoculated with Eisenia foetida at an initial density of $12.5 \mathrm{~g} / \mathrm{L}$. One-inch-diameter perforated polypropylene pipes were installed for the uniform distribution of inflowing wastewater on the top and for the collection of treated wastewater near the bottom.
Sewage from the septic tank on Fudan University campus was fed into the one-stage bio-vermifilter in a batch mode controlled by a timer, and the hydraulic load was kept at $1 \mathrm{~m}^{3} /\left(\mathrm{m}^{2} \cdot \mathrm{d}\right)$ throughout the experiment. During the experiment, pollutant concentrations were measured three times a week after an initial acclimation of 28 days.

\section{Estimation of phosphorous extraction in soils}

A general equation for estimating the amount of extracted phosphorous in soils is shown in Eq. (1):

$\Delta Q=V \times \Delta t$

Where $\Delta Q$ is the amount of phosphorous extracted in soils $(\mathrm{g} / \mathrm{kg}), V$ is phosphorus extraction rate $[\mathrm{g} /(\mathrm{kg}$ month $)]$, and $\Delta t$ is duration (month).

At the same time, total amount of phosphorus extracted in soils $(\Delta Q)$ can be calculated based on the following mass balance equation:

$$
\begin{aligned}
\Delta Q= & \Delta Q_{\mathrm{Labile}-\mathrm{P}}+\Delta Q_{\mathrm{Fe} / \mathrm{Mn}-\mathrm{P}}+\Delta Q_{\mathrm{Al}-\mathrm{P}}+\Delta Q_{\mathrm{OP}_{a l k}} \\
& +\Delta Q_{\mathrm{OP}_{r e s}}+\Delta Q_{\mathrm{Ca} / \mathrm{Mg}-\mathrm{P}}
\end{aligned}
$$

Where $\Delta Q, \Delta Q_{\text {Labile-P }}, \Delta Q_{\mathrm{Fe} / \mathrm{Mn}-\mathrm{P}}, \Delta Q_{\mathrm{Al}-\mathrm{P}}, \Delta Q_{\mathrm{OP}_{\text {alk }}}$, $\Delta Q_{\mathrm{OP}_{r e s}}, \Delta Q_{\mathrm{Ca} / \mathrm{Mg}-\mathrm{P}}$ are the amount of total extracted phosphorus, loosely absorbed phosphorus (Labile-P), phosphorus bounded to $\mathrm{Fe}$ and $\mathrm{Mn}$ compounds (Fe/Mn$\mathrm{P})$, phosphorus bounded to $\mathrm{Al}$ compounds (Al-P), alkaline organic phosphorus without $\mathrm{Al}-\mathrm{P}\left(\mathrm{OP}_{\text {alk }}\right)$, refractory organic phosphorus (Residual-P or $\mathrm{OP}_{\text {res }}$ ), phosphorus bounded to $\mathrm{Ca}$ and $\mathrm{Mg}$ compounds $(\mathrm{Ca} / \mathrm{Mg}-\mathrm{P})$, respectively. Their units are all in $\mathrm{g} / \mathrm{kg}$.
Fig. 1 One-stage biovermifilter used in bench-scale experiments

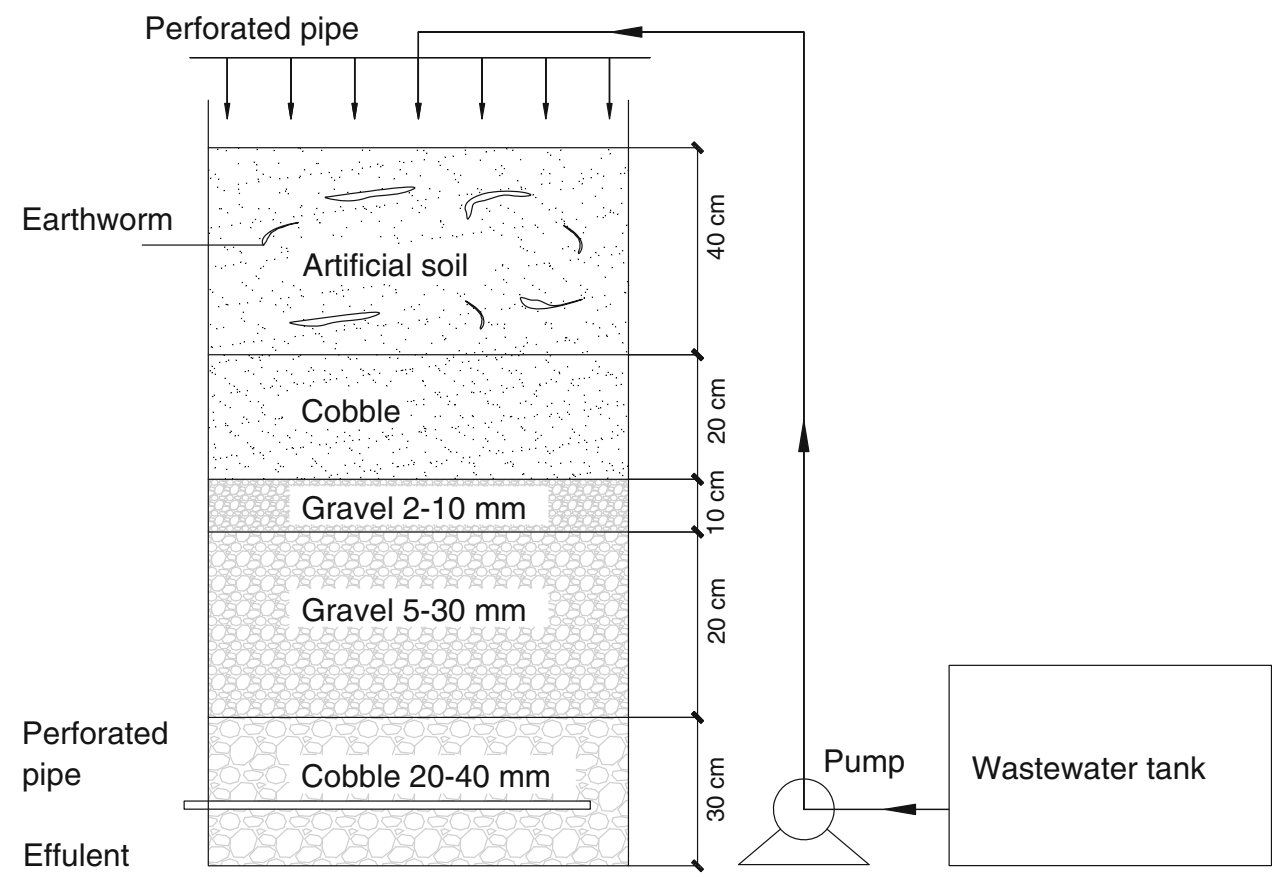


During the 10-month experimental period, the amount of six types of phosphorous extracted by the soils of the one-stage bio-vermifilter was measured three times: at the beginning, 5 months, and 10 months after continuous operation. Based on the measurements of metal concentrations, phosphorus bounding rates of these metal compounds were calculated with Eq. (3).

$M=V / C$

Where $M$ is the phosphorus bounding rate of certain metal compound $(\mathrm{g} /(\mathrm{mol} \cdot \mathrm{month}))$, and $C$ is the concentration of certain metal compound $(\mathrm{mol} / \mathrm{kg})$.

Pilot-scale experiment

During the pilot-scale experiment, one anaerobic biofilter $(20 \mathrm{~cm} \times 100 \mathrm{~cm} \times 160 \mathrm{~cm})$ and two bio-vermifilters $(40 \mathrm{~cm} \times 100 \mathrm{~cm} \times 100 \mathrm{~cm})$ were set up in sequence to treat domestic wastewater from 40 families in a rural village of the Yixing City in Jiangsu province. The anaerobic biofilter contained a $20-\mathrm{cm}$ layer of cobble $(20-40 \mathrm{~mm}$ in diameter) and $80-\mathrm{cm}$ layer of ceramsite $(20-30 \mathrm{~mm}$ in diameter). Each bio-vermifilter contained a $15-\mathrm{cm}$ layer of cobble (20-40 $\mathrm{mm}$ in diameter), 30-cm layer of ceramsite (20-30 $\mathrm{mm}$ in diameter), 5-cm layer of gravel (2-10 mm in diameter), $10-\mathrm{cm}$ layer of sand $(0.2-2 \mathrm{~mm}$ in diameter), and $40-\mathrm{cm}$ layer of AS from the bottom to the top. Naturally ventilated, one-inch polypropylene pipe with holes was installed on the top to ensure uniform distribution of the wastewater, while the other was installed at the bottom to collect treated wastewater at each stage (Fig. 2). Because the whole system looks like a tower, we named it tower bio-vermifilter.

In the pilot tower bio-vermifilter, both bio-vermifilters were inoculated with Eisenia foetida at an initial density of $12.5 \mathrm{~g} / \mathrm{L}$. After an acclimation of 28 days, the pilot tower bio-vermifilter was operated continuously from June to late October at a hydraulic load of $1 \mathrm{~m}^{3} /\left(\mathrm{m}^{2} \cdot \mathrm{d}\right)$.

\section{Engineering applications}

Between 2003 and 2012, more than 50 tower vermifilter systems have been designed, constructed, and operated to treat rural wastewater in three basins of China: Lake Taihu Basin, River Huai Basin, and Lake Erhai Basin. The three basins are all of national significance but with distinctly different characteristics. Lake Taihu is the third largest freshwater lake in China. It is located in the highly developed and densely populated Yangtze River Delta. While accounting for $0.4 \%$ of its land area and $2.9 \%$ of its population, the Lake Taihu basin generates more than $14 \%$ of China's Gross Domestic Production (GDP). Unfortunately, accompanied with the fast economic development, the Lake Taihu is becoming increasingly eutrophied and has been frequently suffering from algae blooms (Yang et al. 2012a, 2012b).

River Huai is the third largest river in China. It is also one of the most seriously polluted rivers in China. According to CMEP (2011), water quality of $43.0 \%$ of its monitored river sections fell between category IV and V of Chinese Environmental Quality Standards for Surface Water (GB 3838-2002), and $15.1 \%$ fell below category V along the River Huai. With around $60 \%$ of rural population, River Huai basin is one of the most rurally populated regions in China.

Lake Erhai is a plateau lake located in the Yunnan province of Southwestern China. It is one of the few lakes in China whose water quality is good enough to meet category III of GB 3838-2002. Different from the other two basins, the largest pollution source in the Lake Erhai basin is livestock. While it has a total population of 800 thousand, the Lake Erhai basin feeds more than 20,000 cows. Large quantity of untreated livestock sewage enters the Lake Erhai, causing sporadic algae blooms in the lake.

To our knowledge, no study has been conducted to analyze these operating tower bio-vermifilter systems' costs and benefits, as well as evaluate their performance in pollutant removal to understand the technology's suitability for wide application in rural wastewater treatment in China. In this study, we selected four operating tower bio-vermifilter systems in the three basins to examine their construction and operation costs, pollutant removal performance, and compared them with two other existing rural sewage treatment technologies to evaluate its suitability for rural sewage treatment in China.

Analytical methods

UV-759S spectrophotometer (Shanghai Precision \& Scientific Instrument Co. Ltd., China) was used to measure the concentrations of COD, $\mathrm{NH}_{4}{ }^{+}-\mathrm{N}, \mathrm{TN}$, and TP of the water samples. Various forms of phosphorus extracted by soils were determined using a five-step sequential extraction scheme (Fang et al. (2010)).

\section{Results and discussion}

Bench-scale experiments

Figure 3 compares the average removal efficiencies of COD, TN, TP, and $\mathrm{NH}_{4}{ }^{+}-\mathrm{N}$ among the seven earthworm bioreactors with different earthworm densities. Average TP removal efficiency kept around $85 \%$, changing little 


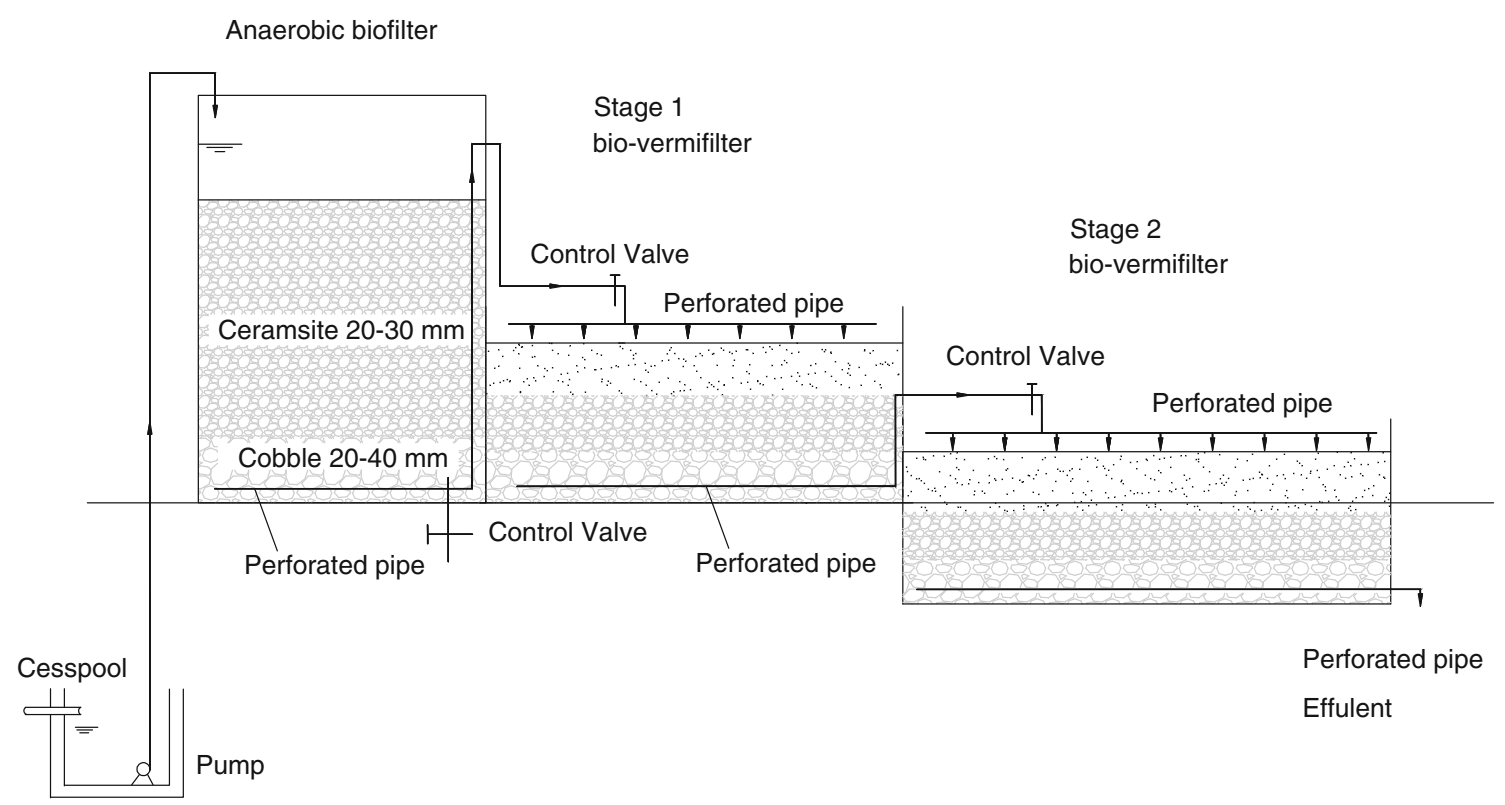

Fig. 2 Pilot tower bio-vermifilter for rural sewage treatment

with earthworm density. Average COD removal efficiency increased steadily from 69.2 to $74.4 \%$ at the earthworm density of $5.0 \mathrm{~g} / \mathrm{L}$, followed by a constant decrease to $67.3 \%$ at the density of $15 \mathrm{~g} / \mathrm{L}$. Average TN and $\mathrm{NH}_{4}{ }^{+}-\mathrm{N}$ removal efficiencies increased constantly with the increase in earthworm density except a leveling off between the density of 12.5 and $15 \mathrm{~g} / \mathrm{L}$. In view of the high cost of earthworms, the best earthworm density was determined to be $12.5 \mathrm{~g} / \mathrm{L}$ for subsequent experiments.

In the soil filter, a column experiment was conducted to examine the changes in TP concentrations at different soil depth after 28 days of acclimation (Fig. 4). TP removal efficiency reached $85 \%$ at the depth of $40 \mathrm{~cm}$, $88.3 \%$ at the depth of $100 \mathrm{~cm}$, and $90.9 \%$ at the depth of $200 \mathrm{~cm}$. This indicated that most of the phosphorous was removed in the upper soil layer. In addition, earthworms are known to inhabit near the surface of the soils (Canti 2003; Paoletti 1999; Wang et al. 2010a). A soil layer of $40 \mathrm{~cm}$ was filled in the subsequent experiments with the one-stage bio-vermifilter and the pilot tower bio-vermifilter.

The one-stage bio-vermifilter was operated for 10 months continuously, and its pollutant removal performance is shown in Fig. 5. The one-stage bio-vermifilter showed a good capability for COD removal. Over the 10-month period, COD concentrations of the effluent could mostly be reduced to less than $100 \mathrm{mg} / \mathrm{L}$ regardless of incoming COD concentrations. However, the onestage bio-vermifilter showed a poor performance in removing nitrogen and phosphorous. Because of the poor performance, the following improvements were made in

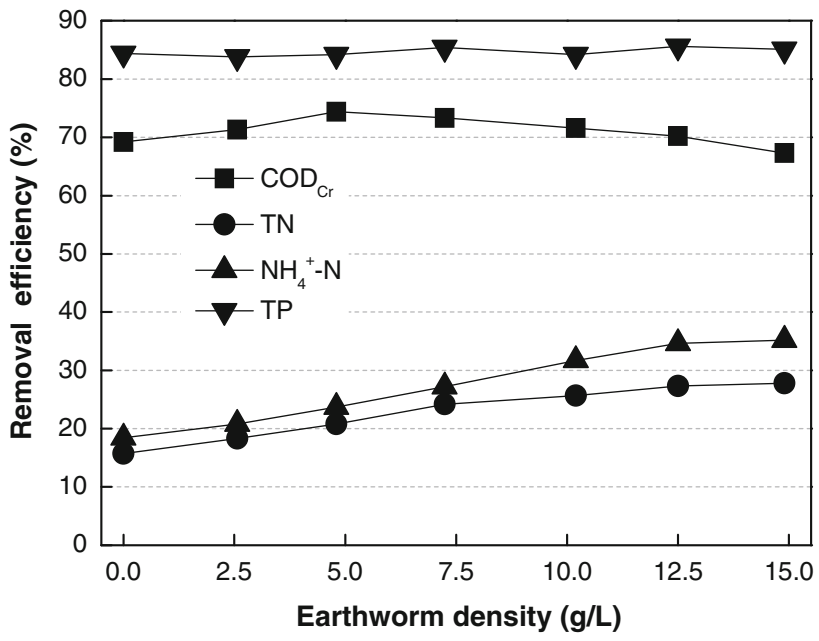

Fig. 3 Effects of earthworm density on the removal of COD, TN, $\mathrm{NH}_{4}{ }^{+}-\mathrm{N}$, and TP in the earthworm bioreactors after 28 days of acclimation

the design of the following pilot-scale experiments: (1) add one anaerobic biofilter at the beginning of the system to improve TN removal efficiency because a high $\mathrm{C} / \mathrm{N}$ ratio is believed to be beneficial to nitrogen removal; (2) add one more bio-vermifilter to increase $\mathrm{NH}_{4}{ }^{+}-\mathrm{N}$ removal efficiencies by improving aeration and facilitating nitration; and (3) change the media of the biovermifilters mainly by replacing gravel with ceramsite, which has high capacity for phosphorous adsorption (Fig. 5).

Figure 6 compares the amount of phosphorus of different forms extracted by the top $(0-10 \mathrm{~cm})$, middle $(10-20 \mathrm{~cm})$, and bottom $(20-40 \mathrm{~cm})$ soil layers in the 


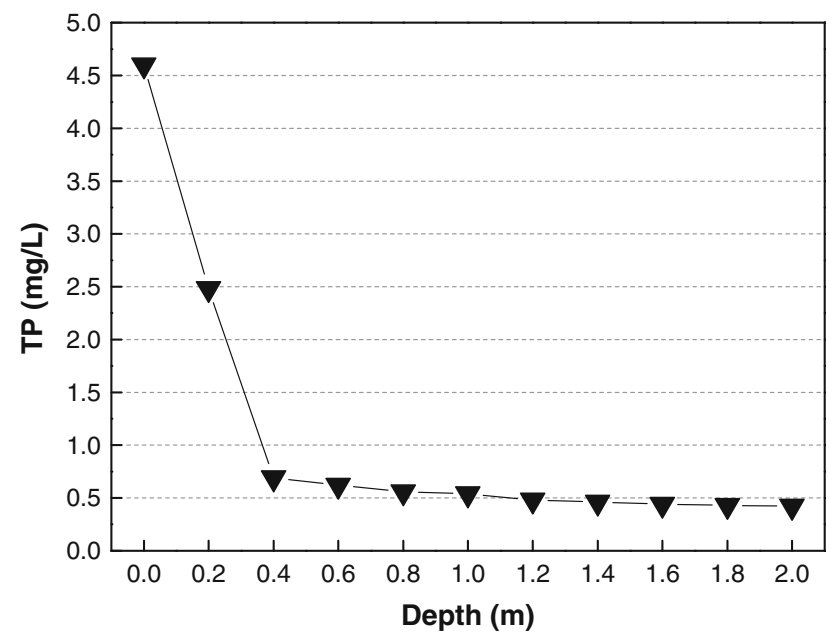

Fig. 4 Changes in TP concentrations at different soil depth in the soil filter after 28 days of acclimation
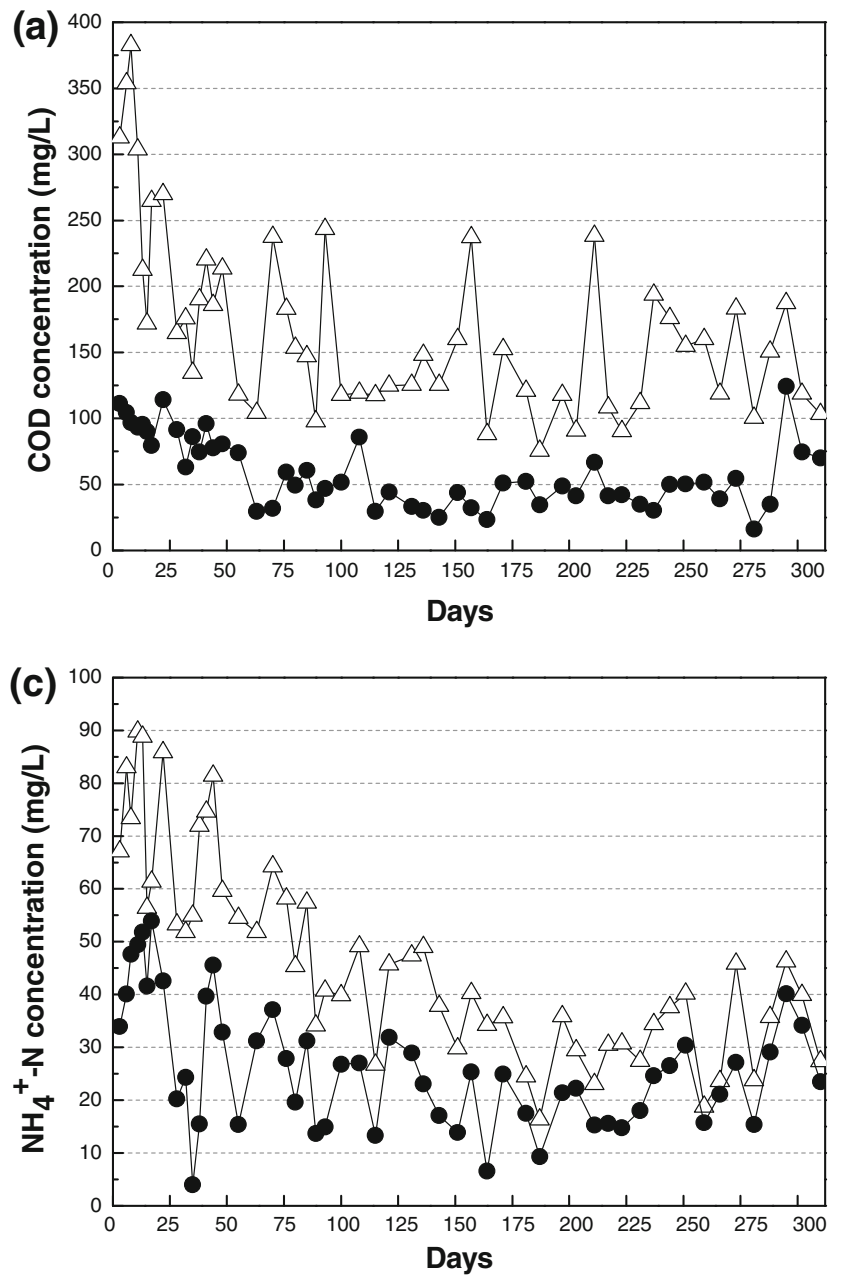

one-stage bio-vermifilter during the first and second 5 months of the experiment. The initial prevailing forms of phosphorus in the soil layers included $\mathrm{OP}_{\text {res }}(317.9 \mathrm{mg} / \mathrm{kg})$, $\mathrm{Ca} / \mathrm{Mg}-\mathrm{P} \quad(230.2 \mathrm{mg} / \mathrm{kg}), \quad \mathrm{Al}-\mathrm{P} \quad(206.1 \mathrm{mg} / \mathrm{kg}), \quad \mathrm{OP}_{\text {alk }}$ $(85.8 \mathrm{mg} / \mathrm{kg}), \quad \mathrm{Fe} / \mathrm{Mn}-\mathrm{P} \quad(59.2 \mathrm{mg} / \mathrm{kg}), \quad$ and Labile-P $(4.2 \mathrm{mg} / \mathrm{kg})$ in a decreasing order. Throughout the experiment, the change in Labile-P was negligible with a maximum value of $17.8 \mathrm{mg} / \mathrm{kg}$. Extracted phosphorous was mainly inorganic and residual phosphorous, which is consistent with Seo et al. (2005) and Wang et al. (2010a). The amount of $\mathrm{OP}_{\text {alk }}$ showed a modest increase of less than 50 and $100 \mathrm{mg} / \mathrm{kg}$ in the first and second 5 months. The amount of $\mathrm{OP}_{\text {res }}$ mostly decreased in the first 5 months, while it showed the largest increase of around $300 \mathrm{mg} / \mathrm{kg}$ in the second 5 months. Change in the content of organic phosphorous was considered to be related to filter media instead of influent (Seo et al. (2005)). In the first 5 months,
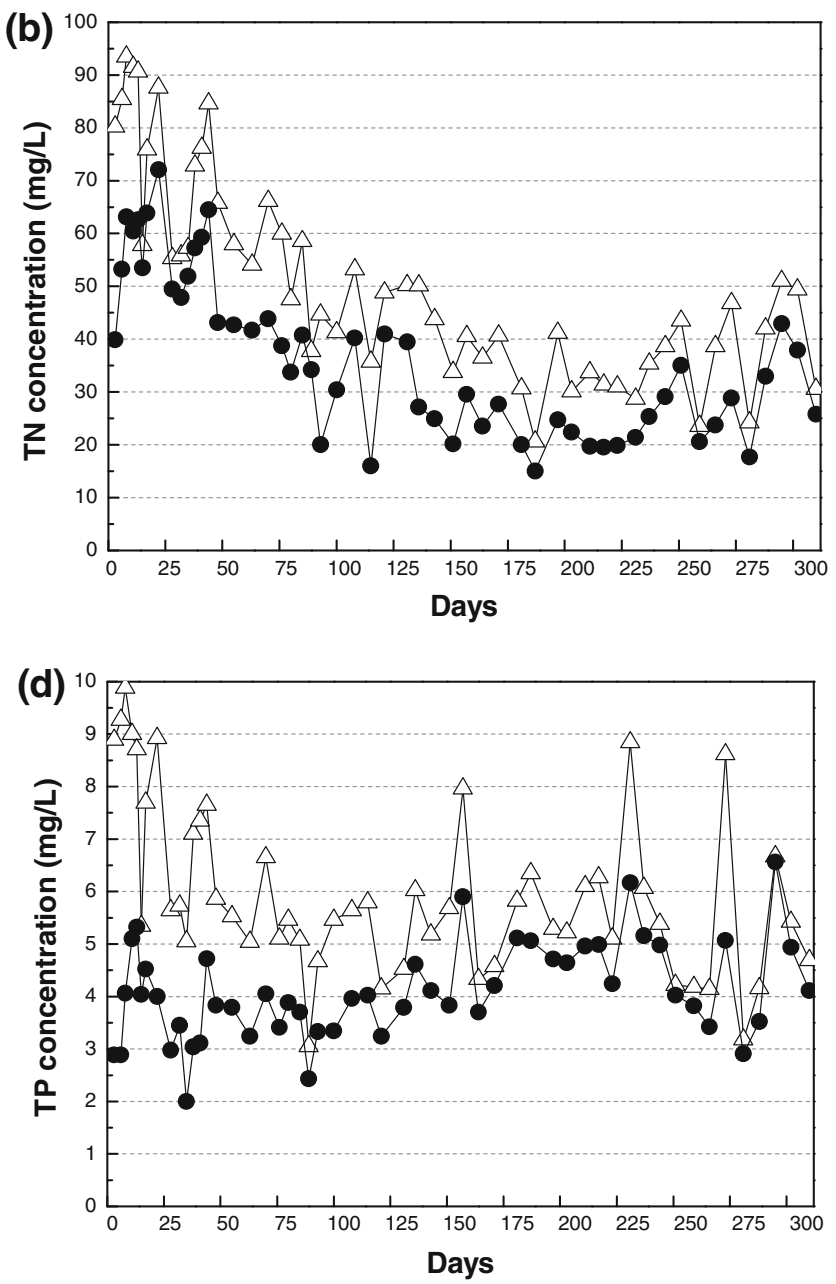

Fig. 5 Change in pollutant concentrations in the influent and effluent of the one-stage bio-vermifilter: a COD, b TN, $\mathbf{c ~} \mathrm{NH}_{4}{ }^{+}-\mathrm{N}, \mathbf{d}$ TP $($ open triangle) influent (filled circle) effluent 
Fig. 6 Change in the content of different forms of phosphorous extracted in the top, middle, and bottom soil layers of the onestage bio-vermifilter during the first and second 5 months

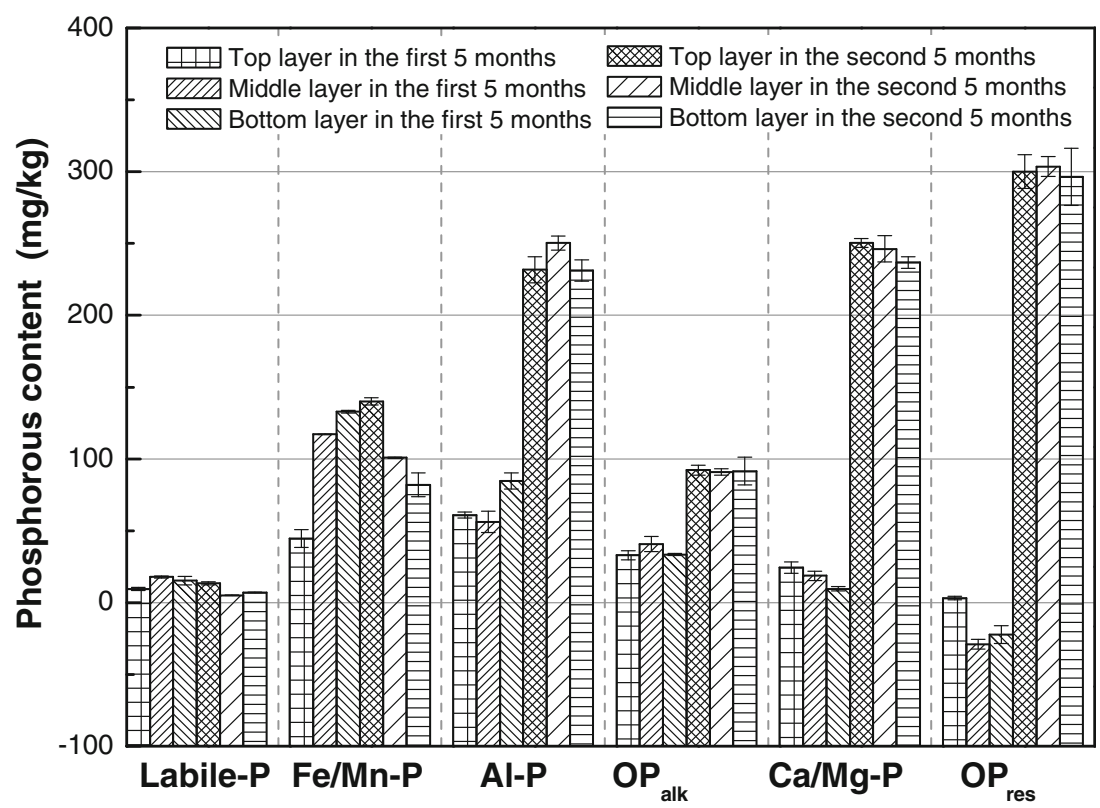

Table 1 Metal concentrations in the soils of the one-stage biovermifilter

\begin{tabular}{lcl}
\hline Compound & Mass content $(\mathrm{g} / \mathrm{kg})$ & Molar content $(\mathrm{mol} / \mathrm{Kg})$ \\
\hline $\mathrm{Ca}(\mathrm{CaO})$ & $9.42 \pm 0.86$ & $0.2355 \pm 0.0215$ \\
$\mathrm{Mg}(\mathrm{MgO})$ & $13.44 \pm 1.81$ & $0.1433 \pm 0.0754$ \\
$\mathrm{Al}\left(\mathrm{Al}_{2} \mathrm{O}_{3}\right)$ & $187.78 \pm 14.61$ & $3.6819 \pm 0.2864$ \\
$\mathrm{Fe}\left(\mathrm{Fe}_{2} \mathrm{O}_{3}\right)$ & $58.61 \pm 9.71$ & $0.7326 \pm 0.1213$ \\
$\mathrm{Mn}(\mathrm{MnO})$ & $1.13 \pm 0.25$ & $0.0159 \pm 0.0035$ \\
\hline
\end{tabular}

an initial excessive amount of organic matter in the soils may lead to a process of phosphorous anti-adsorption. In the second 5 months, the decrease in organic matters due to the digestion of earthworms and soil microorganisms may lead to the large increase of $\mathrm{OP}_{\text {res }}$. As to phosphorous bounded by metal compounds, the increase in $\mathrm{Fe} / \mathrm{Mn}-\mathrm{P}$ was the largest in the first 5 months, but the smallest in the second 5 months. Contrary to $\mathrm{Fe} / \mathrm{Mn}-\mathrm{P}$, there was little increase in $\mathrm{Ca} / \mathrm{Mg}-\mathrm{P}$ in the first 5 months compared to a large increase of around $250 \mathrm{mg} / \mathrm{kg}$ in the second 5 months.

Table 1 gives the initial mass and molar contents of different metal compounds in the soils of the one-stage bio-vermifilter. Using Eq. (3), phosphorous bounding rates by different metal compounds in the top, middle, and bottom soil layers were estimated for the first and second 5 months (Table 2). Its phosphorous bounding rate could act as an indicator of the metal compound's capacity of phosphorous extraction. The general order of the metal compound's phosphorous bounding capacity was $\mathrm{Fe} / \mathrm{Mn}>\mathrm{Ca} / \mathrm{Mg}>\mathrm{Al}$ during the first 5 months, while the order became $\mathrm{Ca} / \mathrm{Mg}>\mathrm{Fe} /$ $\mathrm{Mn}>\mathrm{Al}$ in the second 5 months. This indicated that the bounding between $\mathrm{Fe} / \mathrm{Mn}$ and phosphorus was the fastest, while the ultimate amount of phosphorus bounded per molar of $\mathrm{Ca} / \mathrm{Mg}$ was the largest (Arias et al. 2001; Del Bubba et al. 2003). Hence, in engineering applications, the addition of $\mathrm{Fe} / \mathrm{Mn}$ could improve the bio-vermifilter's phosphorus removal efficiency during its early running, while the addition of $\mathrm{Ca} / \mathrm{Mg}$ is more effective to improve the bio-vermifilter's overall phosphorus removal capacity and extend the system's service time.

\section{Pilot-scale experiments}

A pilot tower bio-vermifilter system was set up and operated to treat rural domestic wastewater collected from a septic tank system in the Yixing City of Jiangsu province for 6 months (May-October) continuously. The system consisted of four components: one anaerobic pond for pretreatment, one anaerobic biofilter, and two bio-vermifilters (stage 1 bio-vermifilter and stage 2 bio-vermifilter) connected in sequence. Figure 7 shows the pollutant concentrations of the influent and the effluent from each of the four components of the system, and the system's overall 
Table 2 Comparison of phosphorous bounding rates by $\mathrm{Fe}$ and $\mathrm{Mn}, \mathrm{Al}$, and $\mathrm{Ca}$ and $\mathrm{Mg}$ at different soil depth (mg/(mol $5 \mathrm{months})$ )

\begin{tabular}{|c|c|c|c|c|c|c|}
\hline & \multicolumn{2}{|l|}{$\mathrm{Fe} / \mathrm{Mn}-\mathrm{P}$} & \multicolumn{2}{|l|}{$\mathrm{Al}-\mathrm{P}$} & \multicolumn{2}{|l|}{$\mathrm{Ca} / \mathrm{Mg}-\mathrm{P}$} \\
\hline & First 5 months & Second 5 months & First 5 months & Second 5 months & First 5 months & Second 5 months \\
\hline Top soil layer & 59.64 & 187.20 & 16.56 & 62.95 & 64.55 & 660.80 \\
\hline Middle soil layer & 156.67 & 134.91 & 15.27 & 67.97 & 49.25 & 650.19 \\
\hline Bottom soil layer & 177.59 & 109.59 & 22.99 & 62.79 & 25.25 & 625.21 \\
\hline
\end{tabular}

(a)
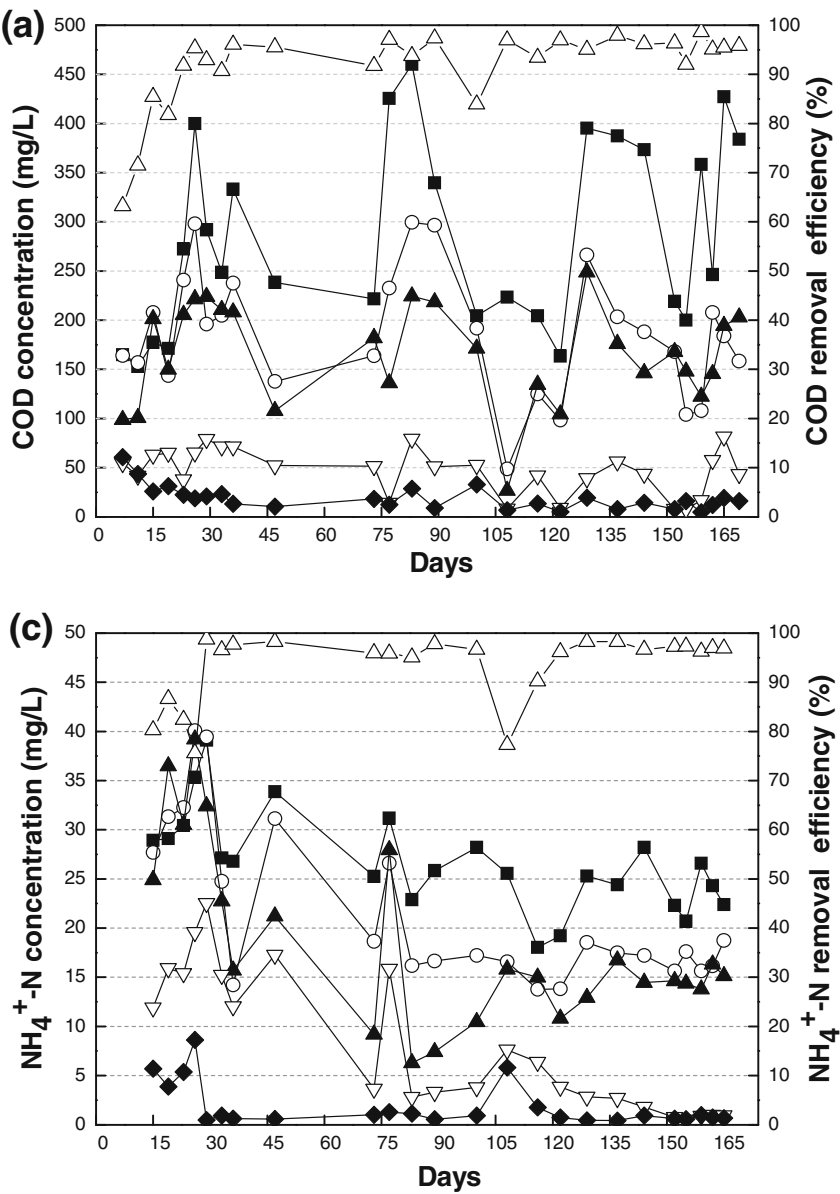

Fig. 7 Pollutant removal by the pilot tower bio-vermifilter system: a COD, b TN, c $\mathrm{NH}_{4}{ }^{+}-\mathrm{N}$, d TP. (filled square)-influent (open circle)—cesspool effluent (filled triangle)—anaerobic biofilter

pollutant removal efficiency over the 6-month experiment period.

The pilot tower bio-vermifilter system showed a good capability for removing COD, with COD removal efficiency remaining over $90 \%$ most of the time. Most of COD had been removed in the effluent from the stage 1 bio-vermifilter. COD concentrations of the effluent from the stage 2 bio-vermifilter kept below $50 \mathrm{mg} / \mathrm{L}$ during the steady operation period, hence meeting the category
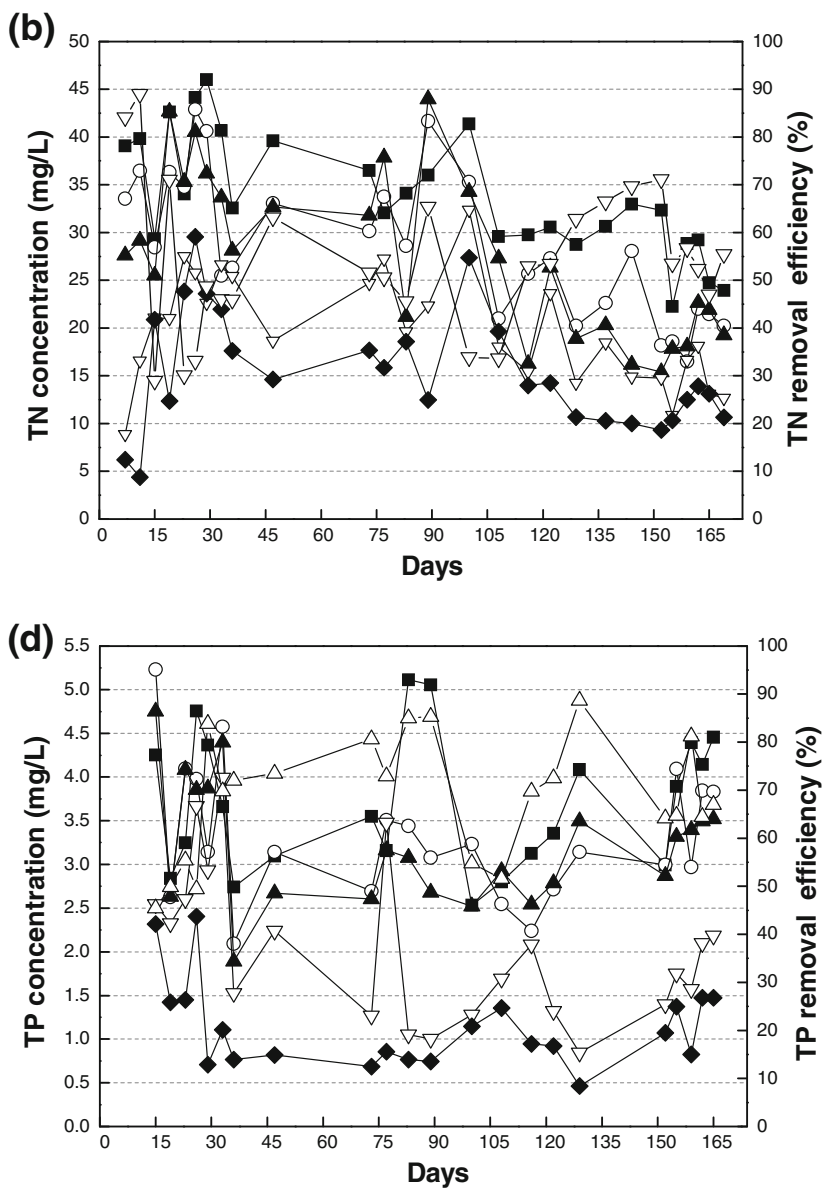

effluent (inverted triangle)—stage 1 bio-vermifilter effluent (filled diamond) —stage 2 bio-vermifilter effluent (filled triangle) - removal efficiency

1A standard for pollutant discharge by municipal wastewater treatment plants of China (GB 18918-2002) (Fig. 7a).

The system's performance in nitrogen removal was mixed. Over the 6 months, TN removal efficiency showed large fluctuations between 30 and $70 \%$ (Fig. 7b). The low TN removal efficiency could be attributed to the low $\mathrm{C} / \mathrm{N}$ ratio of the effluent from the stage 2 bio-vermifilter (Fig. 8). A C/N ratio of less than 
5 is believed to be obstructive to the reduction of nitrates (Misiti et al. (2011)). However, TN concentrations in the effluent were mostly below $20 \mathrm{mg} / \mathrm{L}$, meeting the category 1B standard of GB 18918-2002. Unlike $\mathrm{TN}$, the system performed well in removing $\mathrm{NH}_{4}{ }^{+}-\mathrm{N}$ in terms of both discharge concentrations and removal efficiency. $\mathrm{NH}_{4}{ }^{+}-\mathrm{N}$ removal efficiency remained over $95 \%$ for the most of the time. The removal of $\mathrm{NH}_{4}{ }^{+}-\mathrm{N}$ occurred mostly in the two biovermifilters. $\mathrm{NH}_{4}{ }^{+}-\mathrm{N}$ concentrations of the discharged effluent were mostly below $1.5 \mathrm{mg} / \mathrm{L}$, much less than

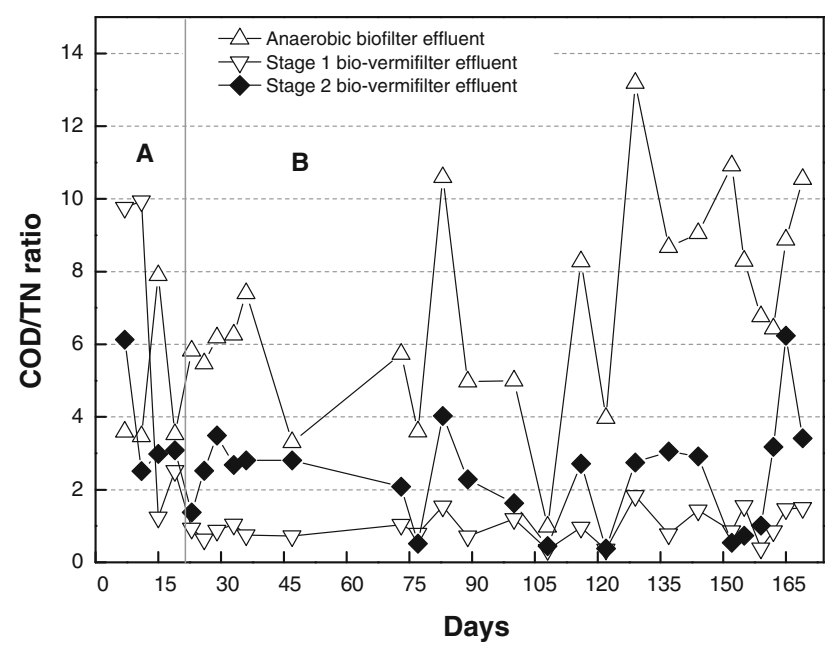

Fig. $8 \mathrm{COD} / \mathrm{TN}$ ratios of the effluent from the anaerobic biofilter, stage 1 bio-vermifilter, and stage 2 bio-vermifilter of the pilot tower bio-vermifilter system the category 1A standard (5 mg/L) of GB 18918-2002 (Fig. 7c).

Like $\mathrm{NH}_{4}{ }^{+}-\mathrm{N}$, the removal of phosphorus occurred mostly in the two bio-vermifilters, indicating phosphorus was largely removed by medium retention. During the experiment, TP removal efficiencies fluctuated between 50 and $90 \%$, and TP concentrations of the effluent was less than $1.5 \mathrm{mg} / \mathrm{L}$ most of the time (Fig. 7d).

\section{Engineering applications}

Four operating tower bio-vermifilter systems in the Lake Taihu Basin, River Huai Basin, and Lake Erhai Basin were evaluated for their performance in rural wastewater treatment. In addition, published data on two other rural sewage treatment facilities [cyclic activated sludge system (CASS) and subsurface soil infiltration system] in the economically developed Yangtz Delta of China were used for comparison (Hao et al. 2010; Hao and Zhang 2010). CASS process is a recirculation activated sludge process, which proceeds in cycles consisting of aeration, sedimentation, and discharge. Subsurface soil infiltration system is a land treatment process, which depends on the synergistic reactions among microorganisms, plants, and soils to remove pollutants (Table 3).

The four evaluated tower bio-vermifilters ranged from 1.8 to $3.6 \mathrm{~m}$ in height, 20 to $83.2 \mathrm{~m}^{2}$ in size, and 24 to $200 \mathrm{~m}^{3} /$ day in treatment capacity depending on the number of people and livestock served. The original design capacity of the tower bio-vermifilter in the Erhai Basin (Site 4) was $50 \mathrm{~m}^{3} /$ day. Nevertheless, the actual

Table 3 Characteristics of the tower bio-vermifilter systems and two comparing rural sewage treatment systems

\begin{tabular}{|c|c|c|c|c|c|c|c|c|}
\hline Site & Technology & Location & $\begin{array}{l}\text { Size } \\
\left(\mathrm{m}^{2}\right)\end{array}$ & $\begin{array}{l}\text { Treatment } \\
\text { capacity } \\
\left(\mathrm{m}^{3} / \mathrm{d}\right)\end{array}$ & $\begin{array}{l}\text { Type of } \\
\text { wastewater }\end{array}$ & $\begin{array}{l}\text { People/animals } \\
\text { served }\end{array}$ & $\begin{array}{l}\text { Construction } \\
\text { cost }^{\mathrm{a}} \\
{\left[\mathrm{RMB} /\left(\mathrm{m}^{3} / \mathrm{d}\right)\right]}\end{array}$ & $\begin{array}{l}\text { Electricity } \\
\text { consumption } \\
\left(\mathrm{KWh} / \mathrm{m}^{3}\right)\end{array}$ \\
\hline Site 1 & Tower bio-vermifilter & $\begin{array}{l}\text { TaiCang, Jiangsu } \\
\text { province }\end{array}$ & 49 & 40 & Domestic sewage & 230 people & 3522 & 0.11 \\
\hline Site 2 & Tower bio-vermifilter & $\begin{array}{c}\text { Changzhou, } \\
\text { Jiangsu } \\
\text { province }\end{array}$ & 20 & 24 & Domestic sewage & 240 people & 6,242 & 0.13 \\
\hline Site 3 & Tower bio-vermifilter & $\begin{array}{l}\text { Zhumadian, } \\
\text { Henan province }\end{array}$ & 58 & 50 & Domestic sewage & 1,000 people & 3,212 & 0.09 \\
\hline Site 4 & Tower bio-vermifilter & $\begin{array}{l}\text { Dali, Yunnan } \\
\text { province }\end{array}$ & 83.2 & $200^{\mathrm{b}}$ & $\begin{array}{l}\text { Domestic and } \\
\text { livestock sewage }\end{array}$ & $\begin{array}{l}\text { 3,338 people } \\
\text { and } 700 \text { cow }\end{array}$ & 1,466 & 0.06 \\
\hline Site 5 & CASS & $\begin{array}{l}\text { Suzhou, Jiangsu } \\
\text { province }\end{array}$ & 50 & 100 & Domestic sewage & / & 5,700 & 0.16 \\
\hline Site 6 & $\begin{array}{l}\text { Subsurface soil } \\
\text { infiltration system }\end{array}$ & Shanghai & 350 & 51 & Domestic sewage & 484 people & 5,128 & 0 \\
\hline
\end{tabular}

a The estimates of the construction costs were extracted from the government's accounting reports after the completion of the rural sewage treatment projects. Construction costs include the costs of labors in construction, construction materials (such as cement, bricks, sands, etc.), and equipment (such as pumps)

b Actual treatment capacity. The original design capacity of the system was $50 \mathrm{~m}^{3} /$ day 
Table 4 Pollutant removal by the tower bio-vermifilter systems (mg/L)

\begin{tabular}{|c|c|c|c|c|c|c|c|c|}
\hline \multirow[t]{2}{*}{ Site } & \multicolumn{2}{|l|}{ COD } & \multicolumn{2}{|l|}{$\mathrm{TN}$} & \multicolumn{2}{|l|}{$\mathrm{NH}_{4}^{+}-\mathrm{N}$} & \multicolumn{2}{|l|}{$\mathrm{TP}$} \\
\hline & Influent & Effluent & Influent & Effluent & Influent & Effluent & Influent & Effluent \\
\hline Site 1 & 184 & 7 & 26.1 & 0.935 & 23.6 & 0.401 & 2.36 & 0.338 \\
\hline Site 2 & 98.24 & 32.12 & 20.887 & 8.503 & 1.292 & 0.753 & 2.981 & 0.413 \\
\hline Site 3 & 182 & 36.1 & 32.6 & 6.37 & 18.9 & 1.36 & 4.68 & 0.61 \\
\hline Site 4 & 685 & 100 & 87.1 & 11.1 & l & I & 7.61 & 0.88 \\
\hline
\end{tabular}

hydraulic load of the system was $200 \mathrm{~m}^{3} /$ day, treating sewage from more than 3,000 people and 700 cows. The CASS system's size and treatment capacity were comparable to the four tower bio-vermifilters. The size of the subsurface soil infiltration system was more than four times the other systems, since land treatment systems normally require a large space for pollutant treatment (Table 3).

Unit treatment capacity cost of the four tower bio-vermifilter systems ranged from 1466 to $6242 \mathrm{RMB} /\left(\mathrm{m}^{3} / \mathrm{d}\right)$ mainly due to the difference in the materials used for constructing the tower bio-vermifilters. One tower biovermifilter in the Lake Taihu Basin (Site 1) and the one in the River Huai Basin (Site 3) were made of brick and concrete, while the other tower bio-vermifilter in the Lake Taihu Basin (Site 2) and the one in the Lake Erhai Basin (Site 4) were made of fiberglass-reinforced plastics. Despite made of fiberglass-reinforced plastics, the unit treatment capacity cost of the tower bio-vermifilter system was much lower in the Erhai Basin because of the overloading of the system. Generally speaking, the unit treatment capacity cost of the tower bio-vermifilter systems was lower than the CASS and the subsurface soil infiltration system if they were made of brick and concrete, but higher than the other two systems if made of fiberglass-reinforced plastics.

Electricity is needed to operate the tower bio-vermifilter system and CASS. In the tower bio-vermifilter system, electricity is consumed mainly to lift wastewater to a height of 3-5 m. Electricity consumption for treating $1 \mathrm{~m}^{3}$ of wastewater ranged from 0.06 to $0.13 \mathrm{kWh}$ among the four tower bio-vermifilter systems, all lower than the CASS system which requires additional electricity for aeration.

Monitoring data on the water quality of the four tower bio-vermifilter systems' influent and effluent were obtained from local environmental protection agencies (Table 4). Effluent from the three systems in the Lake Taihu and River Huai basins could all meet the category 1A standard of GB 18918-2002. In the Lake Erhai basin, COD concentrations of the effluent could not meet the category $1 \mathrm{~A}$ standard. This is largely due to the overloading of the system, since the amount of influent was four times the original design capacity of the system. The two comparing systems were reported to be able to meet the category $1 \mathrm{~B}$ standard of GB 18918-2002. Overall, field data of the four tower bio-vermifilter systems indicated a satisfactory performance in pollutant removal at a comparable or even lower construction and operation cost than the other two systems.

\section{Conclusion}

Pervasive discharge of untreated rural wastewater is a serious issue threatening China's water security. Development of suitable rural wastewater treatment technologies is the premise to the improvement of the aggravating rural environment in the country. In this study, a novel tower bio-vermifilter system for rural sewage treatment has been systematically examined at three scales: benchscale, pilot-scale, and engineering applications. Benchscale studies led to the determination of the most appropriate earthworm density (12.5 g/L) (Fig. 3) and the best soil depth $(40 \mathrm{~cm})$ (Fig. 4) for pilot and engineering applications. In addition, the analysis of different forms of phosphorous in the one-stage bio-vermifilter showed that the largest amount of phosphorous was bounded by $\mathrm{Ca} /$ $\mathrm{Mg}$, suggesting the addition of $\mathrm{Ca} / \mathrm{Mg}$ to improve the biovermifilter's overall phosphorous removal capacity (Table 2).

Operating results of the pilot tower bio-vermifilter system showed a good performance in the removal of COD, $\mathrm{NH}_{4}{ }^{+}-\mathrm{N}$, and phosphorous. COD concentrations of the discharge were mostly less than $50 \mathrm{mg} / \mathrm{L}$, while $\mathrm{NH}_{4}{ }^{+}-\mathrm{N}$ and phosphorous concentrations mostly less than $1.5 \mathrm{mg} / \mathrm{L}$. However, the system's removal of TN showed considerable fluctuations, although TN concentrations of the discharge were mostly able to meet the category $1 \mathrm{~B}$ standard of GB 18918-2002 (Fig. 7). A low C/N ratio in the stage 2 bio-vermifilter could be one reason for the fluctuating TN removal efficiencies. As a potential solution, some raw sewage may be added to the inflow of the stage 2 biovermifilter to increase its $\mathrm{C} / \mathrm{N}$ ratio to enhance the nitration process. 
Four operating tower vermifilter systems were compared with the CASS system and the subsurface soil infiltration system in terms of economic cost and pollutant removal performance. Comparison results have shown that the tower bio-vermifilter systems are able to treat rural sewage effectively under a variety of natural and socioeconomic conditions at a reasonably low cost (Tables 3 and 4). Due to its advantages of low cost, easy operation, and versatility, the tower bio-vermifilter system has great potentials for wide applications in rural wastewater treatment in China and possibly other developing countries.

Acknowledgments The authors would like to acknowledge the financial support provided by Shanghai Natural Science Foundation (Grant Number: 11ZR1402900), Fudan University 985 project (Grant Number: 2012SHKXQN009), Chinese Natural Science Foundation (Grant Number: 41201191), and Chinese Ministry of Education New Faculty Fund (Grant Number: 20120071120034).

\section{References}

Arias CA, Del Bubba M, Brix H (2001) Phosphorus removal by sands for use as media in subsurface flow constructed reed beds. Water Res 35(5):1159-1168

Canti MG (2003) Earthworm activity and archaeological stratigraphy: a review of products and processes. J Archaeol Sci 30(2):135-148

Chinese Ministry of Environmental Protection (CMEP) (2011) The State of Environment in China, March 13. http://jcs.mep.gov.cn/ hjzl/zkgb/ (in Chinese)

Conley DJ, Paerl HW, Howarth RW, Boesch DF, Seitzinger SP, Havens KE, Lancelot C, Likens GE (2009) Controlling eutrophication: nitrogen and phosphorus. Science 323(5917): $1014-1015$

Del Bubba M, Arias CA, Brix H (2003) Phosphorus adsorption maximum of sands for use as media in subsurface flow constructed reed beds as measured by the Langmuir isotherm. Water Res 37(14):3390-3400

Duan H, Ma R, Xu X, Kong F, Zhang S, Kong W, Hao J, Shang L (2009) Two-decade reconstruction of algal blooms in China's Lake Taihu. Environ Sci Technol 43(10):3522-3528

Fang CX, Zheng Z, Luo XZ, Guo FH (2010) Effect of hydraulic load on domestic wastewater treatment and removal mechanism of phosphorus in earthworm ecofilter. Fresen Environ Bull 19(6): 1099-1108

Fang CX, Guo FH, Luo XZ, Chen GY, Zheng Z (2011) Performance of a three-stage tower earthworm ecofilter for simultaneous removal of carbon and nutrients from domestic wastewater. Fresen Environ Bull 20(1A):235-243

Guo L (2007) Doing battle with the green monster of Taihu Lake. Science 317(5842):1166

Hao Q, Zhang P (2010) Cost effectiveness analysis of rural domestic sewage treatment projects: a case study in Shanghai and southern Jiangsu province. China Popul Resour Environ 20(1):108-111 (in Chinese)

Hao Q, Guo S, Zhang P (2010) The popularization analysis of rural domestic sewage land treatment projects-a case study in Shanghai and southern Jiangsu area. Environ Sci Manage 35(5):80-82,109 (in Chinese)

Li S, Li H, Liang XQ, Chen YX, Wang SX, Wang FE (2009) Phosphorus removal of rural wastewater by the paddy-rice- wetland system in Tai Lake Basin. J Hazard Mater 171(1-3): 301-308

Liang H, Gao M, Liu J, Wei Y, Guo X (2010a) A novel integrated step-feed biofilm process for the treatment of decentralized domestic wastewater in rural areas of China. J Environ Sci 22(3):321-327

Liang H, Liu J, Wei Y, Guo X (2010b) Evaluation of phosphorus removal from wastewater by soils in rural areas in China. J Environ Sci 22(1):15-22

Ma JT (2012) 2012 International statistical year book. China Statistics Press, Beijing, pp. 116 (in Chinese)

Misiti TM, Hajaya MG, Pavlostathis SG (2011) Nitrate reduction in a simulated free-water surface wetland system. Water Res 45(17): $5587-5598$

Otten TG, Xu H, Qin B, Zhu G, Paerl HW (2012) Spatiotemporal patterns and ecophysiology of toxigenic Microcystis blooms in Lake Taihu, China: implications for water quality management. Environ Sci Technol 46(6):3480-3488

Paerl HW, Huisman J (2008) Blooms like it hot. Science 320(5872):57-58

Paoletti MG (1999) The role of earthworms for assessment of sustainability and as bioindicators. Agr Ecosyst Environ 74(1-3): 137-155

Seo DC, Cho JS, Lee HJ, Heo JS (2005) Phosphorus retention capacity of filter media for estimating the longevity of constructed wetland. Water Res 39(11):2445-2457

Sinha RK, Bharambe G, Chaudhari U (2008) Sewage treatment by vermifiltration with synchronous treatment of sludge by earthworms: a low-cost sustainable technology over conventional systems with potential for decentralization. Environmentalist 28(4):409-420

Verbyla ME, Oakley S, Mihelcic J (2013) Wastewater infrastructure for small cities in an urbanizing world: integrating the protection of human health and the environment with resource recovery and food security. Environ Sci Technol (in Press)

Wang G, Wu L, Xu X, Jin Q, Li X (2010a) Influence of Eisenia foetida on biomass and urease activity in vertical constructed wetland. J Southeast Univ 40(5):1013-1018 (in Chinese)

Wang L, Zheng Z, Luo X, Zhang J (2010b) The current pollution status and control technology of the Taihu Lake Basin, Jiangsu Province China. Int J Environ S 67(2):195-205

Wang C, Lu G, Peifang W, Wu H, Qi P, Liang Y (2011a) Assessment of environmental pollution of Taihu Lake by combining active biomonitoring and integrated biomarker response. Environ Sci Technol 45(8):3746-3752

Wang L, Guo F, Zheng Z, Luo X, Zhang J (2011b) Enhancement of rural domestic sewage treatment performance, and assessment of microbial community diversity and structure using tower vermifiltration. Bioresource Technol 102(20):9462-9470

Wang L, Zheng Z, Luo X, Zhang J (2011c) Performance and mechanisms of a microbial-earthworm ecofilter for removing organic matter and nitrogen from synthetic domestic wastewater. J Hazard Mater 195:245-253

Wang L, Luo XZ, Zhang Y, Chao J, Gao Y, Zhang JB, Zheng Z (2013) Community analysis of ammonia-oxidizing Betaproteobacteria at different seasons in microbial-earthworm ecofilters. Ecol Eng 51:1-9

Wei B, Sugiura N, Maekawa T (2001) Use of artificial neural network in the prediction of algal blooms. Water Res 35(8):2022-2028

Wu S, Austin D, Liu L, Dong R (2011) Performance of integrated household constructed wetland for domestic wastewater treatment in rural areas. Ecol Eng 37(6):948-954

Xin H, Stone R (2010) China amasses war chest to confront its environmental nightmares. Science 327(5972):1440-1441

Yang M, Yu J, Li Z, Guo Z, Burch M, Lin T (2008) Taihu Lake not to blame for Wuxi's woes. Science 319(5860):158a 
Yang X, Fang S, Lant CL, Luo X, Zheng Z (2012a) Overfertilization in the economically developed and ecologically critical Lake Tai Region China. Hum Eco 40(6):957-964

Yang X, Jiang G, Luo X, Zheng Z (2012b) Preliminary mapping of high-resolution rural population distribution based on imagery from Google Earth: a case study in the Lake Tai basin, eastern China. Appl Geogr 32(2):221-227

Zhang L, Liu W, You B, Bian B (2009) Characteristics of pollutant sources of Caoqiao River in Taihu Lake Basin. Res Environ Sci 10(22):1150-1155 (in Chinese) 